\title{
THE USES OF LOCAL HISTORY IN THE AMERICAN HISTORY SURVEY
}

Jerold Simmons

University of Nebraska at Omana

Those of us who lecture to large undergraduate classes in American history are engaged in a seemingly never-ending search for ways to enhance student interest in the American past. As part of that quest, we peruse Teaching History and other professional journals in the hope of finding new ideas and techniques, but most of the suggestions we find are geared toward use in relatively small survey classes. Unfortunately, many of us are still bound by the restrictions of the large lecture course and with it the inevitably imposing lecture hall with row upon row of fixed seats faced by a single immoveable lectern. It is very difficult to employ sophisticated simulation games, role-playing techniques, and the like in this environment. The room itself, along with the seemingly countless bodies which fill those fixed seats, virtually dictates the lecture method of instruction, and the credithour production concerns of deans, trustees, and state legislators almost certainly insure the continued use of this method for the foreseeable future.

For those of us who teach in this environment, who are forced to operate within the restrictive confines of the lecture format, the problem can be stated quite simply. How does one provide reasonably analytical, yet understandable, accounts of the American past in lecture form which are sufficiently stimulating to hold a student's interest for fifty minutes? Obviously, in an age of television and other instant diversions, this is no mean task, and it is rendered even more difficult by the fact that most of our students have enrolled in the course not out of any compelling desire to learn about our common heritage, but in order to satisfy a graduation requirement which, in most cases, they resent. They see no particular relationship between the American past and their own experience, and hence have little incentive, short of grades, to take the course seriously. They are, in other words, a very difficult audience to stimulate.

Most of us who teach the survey have adapted to this reality by complementing our lectures with a variety of audio-visual aids and by spicing our presentations with anecdotes and illustrations. But tapes, slide presentations, and humorous stories can only go so far. They may heighten interest in the lecture, but they do little to establish that personal relevance of the material which is so essential for effective learning.

The U.S. survey, by definition, must focus upon broad regional and national themes which are difficult for students to grasp. Such themes are too abstract, too remote from the students' personal world to have any direct meaning for them. As a consequence, they often find the class irrelevant and boring, and its content difficult to master. There is, however, a remedy at hand--a means of establishing that personal relevance which can make these broad abstractions more interesting and meaningful to the student audience. That remedy is local history. The use of local examples in the survey, rather than the more distant illustrations afforded by most texts, can provide that essential link between the listener and the abstract themes being developed. It can transfer those themes from a remote, unknown realm to a more specific and concrete locale which students can both visualize and understand. And by demonstrating the interrelationship between local and national developments, this approach enables the instructor to dramatize the relevance of such themes to the student's immediate experience.

This is hardly a new idea. Historians have long recognized the value of local illustrations in highlighting broader themes, and elementary and secondary teachers have made great strides in using local history projects to generate student interest. Yet few college instructors have followed this 
path. This is unfortunate because the dividends to be derived from the systematic use of local examples in the survey can be substantial. While I have only begun to explore the potential of this approach in my own survey classes at the University of Nebraska at Omaha, I can state with certainty that its use has both heightened student interest and improved the understanding of the processes and themes I seek to explore. One or two illustrations should suffice.

When I first began lecturing in the freshman survey, I developed what I thought was a highly relevant and interesting lecture on the emergence and operations of urban political machines, replete with examples and illustrations drawn from the excellent body of secondary literature on the topic. Unfortunately very few students seemed to share my perception. They had little interest in the operations of Tammany Hall or the Pendergast Machine, found my quotations from George Washington Plunkitt only mildly amusing, and before long were gazing longingly out the window or more anxiously at the clock on the wall behind me. Several years ago, however, I injected a reference to the political machine which operated in Omaha at the turn of the century, and suddenly the gazing and fidgeting ceased. Students were startled to discover that Omaha had its own highly sophisticated machine and seemed fascinated by its operation. A number detained me after class with questions and requests for more details. The lesson was obvious. So I laid Plunkett aside and concentrated my attention on the Omaha machine. Fortunately a colleague in the Political Science Department was just completing an extensive study of the local machine, and with his assistance I was able to build the entire lecture around the local experience. The generalizations remained the same; only the specific examples and illustrations were changed so as to establish the local relevance of this broader topic. I continued to emphasize the social, economic, and political conditions which gave rise to machine politics, but illustrated these conditions with Omaha examples. The results were all I expected. Student interest in the lecture increased dramatically, and the essays they wrote reflected a much fuller grasp of political machines.

This success caused me to wonder whether I could apply the same approach to other topics. Consequently I began a systematic review of local sources with an eye toward the survey, searching for information which could be used to illustrate larger national themes. The results have been well worth the effort. Today I no longer discuss the dramatic increase of racial tension in American cities following World War I in terms of Chicago or Detroit but focus instead on Omaha. The local pattern was quite similar to those in other cities. The mounting white concern over jobs, housing, and miscegenation were clearly reflected in the local press and were manifested, as elsewhere, in a violent riot directed at the Black community during the summer of 1919 . I highlight this lecture with brief quotations from local newspapers and identify specific locations and conditions so that the students can form a more precise image of both the riot and what it was like to be Black in Omaha in the early twentieth century.

I have also attempted to demonstrate the interrelationship between local and national developments by focusing upon the local impact of national political programs. This approach is particularly useful when applied to the New Deal. I set the stage for my. New Deal lecture with an examination of depression conditions in eastern Nebraska in 1932, citing local statistics on unemployment, business failures, and farm foreclosures, and attempt to translate these dry statistics into the personal tragedies they represent through descriptive passages from the local press and personal interviews. Then, after describing New Deal legislation, I focus upon the local implementation of specific programs. By detailing the activities of the CWA and WPA in Omaha, and by demonstrating the way in which the National Labor Relations Act fostered the development of local unions, I am better able to convey a 
sense of the New Deal's larger impact. This focus also enables me to trace the changing perceptions of the New Deal held in the Midwest. Once again I use local voting data, interviews, and editorials to show how Nebraskans moved from overwhelming enthusiasm for New Deal experimentation in 1934, through a period of increasing skepticism to outright rejection by 1940. This then prepares the students for a return to the national scene and a look at the formation of the conservative coalition in Congress.

The interrelationship between local and national developments is also easily illustrated by examining the local impact of World War II and the Cold War in the form of Omaha's burgeoning military establishment. Bellevue, a southern suburb, represents a typical World War II boom town, and an examination of its transformation in the wake of the location of a major bomber plant there in 1940 illustrates the enormous domestic problems and potentials the war created for small towns. The fact that Bellevue was later selected as the headquarters for the Strategic Air Command allows carrying this theme into the postwar era and provides the students with a graphic illustration of the domestic impact of the Truman and Eisenhower defense programs.

The list of examples could go on, but the important point is not what examples were used, but how they were used. In each case, local illustrations were employed in order to make national themes and events more interesting and understandable. By translating these themes and events from the abstract and distant to the concrete and local, they become more relevant and more memorable. Whether machine politics, racial tension, or the impact of the New Deal, the point seemed to stick much better when applied with concrete local examples.

Obviously, this approach to the survey is easiest to apply at a large urban university where the students are drawn from a relatively defined locality and share a common heritage. This allows the instructor to draw student attention to a district or neighborhood, or even to a specific street or building, knowing that most will have at least some visual image of the locale. In addition, the urban setting provides the kinds of examples necessary to illustrate many broader survey themes, especially twentieth-century themes. It would be much more difficult to find local examples to portray machine politics or emerging racial tensions, if one taught at an institution located in a small midwestern community. But local illustrations can still be valuable. The impact of the New Deal, for example, could be viewed just as easily from a rural as an urban perspective. The emphasis might shift from the activities of the National Labor Relations Board to those of the Agricultural Adjustment Administration or Rural Electrification Administration, but the thrust of the lecture would be the same. A rural setting might also afford excellent local examples through which to examine frontier society, early settlement patterns, town building, and other colonial and nineteenth-century topics. Moreover, the students of even the most remote institution are usually acquainted with at least one regional metropolis and might show more interest if urban examples were selected from that metropolis rather than some more distant city.

This is not meant to suggest that the survey be converted into a course in local history or even that local examples should come to dominate survey lectures. Indeed, if that were to happen, the students could lose one of the primary benefits which the survey so effectively provides--that sense of the breadth and diversity of the American experience. For that reason care must be exercised in the selection of local examples. The instructor dare not choose items simply because they might prove interesting or amusing but must instead insure that each does in fact contribute to that broader understanding of the American past that we all seek to impart. Similarly, one must take care to avoid the distortion and over-simplication which can accompany the use 
of local examples in the survey. Many may not adequately convey the complexity or diversity of the topic under consideration. One would be hardpressed, for example, to provide a full or even adequate image of American progressivism through local illustrations alone. That phenomenon is so complex and its manifestations so varied across the country, that no one locality could ever provide sufficient examples to convey the whole picture, The activities of Omaha progressives can be used to illustrate the broader progressive desire to eliminate boss control of urban government, their penchant for tampering with the structure of government, and their failure to address the problems of the urban poor, but the progressive experience in Omaha portrays only a small part of the much larger and more complex progressive national portrait. Thus, the Omaha experience must be balanced by examples from other regions and localities for the full picture to emerge. One must also take care not to force local examples into national patterns where they do not fit. Frequently, local conditions so distort a given development that such examples serve to confuse rather than enlighten the student. Omaha's late nineteenth-century immigration and mobility patterns, for example, are sufficiently different from the national norm as to render them next to useless as a basis for examining those broader themes. In this case, local developments were characteristic of patterns emerging in cities of similar size in the Midwest but were hardly effective in conveying the total national picture. Consequently, their use in the survey proved counterproductive.

Yet this merely suggests that the instructor select and use his local examples with great care. They do not work in all situations. They are no more a panacea than humorous stories or visual materials. Like any other tool one uses to stimulate interest, local illustrations should only be employed where they can contribute to the learning process.

Unfortunately, it is a good deal easier to advocate the use of local illustrations than to employ this approach in practice. The collection of relevant local material does require a substantial investment of time and energy. Most of us are not specialists in local history, and few have more than a passing acquaintance with or interest in the history of our own communities. We have not heeded the authors of the Harvard Guide to American History, who recommended that every Americanist pursue "a sideline of local history."I Thus, we must develop that sideline from scratch. If the community has attracted significant scholarly attention, this may not be difficult. Few of us, however, are so fortunate as to have a large volume of readily available published material to draw on. Instead, most will be forced to search through more remote sources--through the journals and proceedings of state and local historical societies, the masters and doctoral theses produced at nearby universities, and even the often unreliable subscription histories of the late nineteenth, and early twentieth centuries.

In most communities, however, even the most exhaustive review of existing literature is unlikely to produce more than a few illustrations. The focus of most local studies is quite narrow, and few develop the relationship between the national and local scenes which is so crucial to this approach to the survey. As a consequence, the instructor will be forced to carry his search beyond such secondary accounts into the primary sources of history. He will, in other words, need to design modest research projects to fit the needs of his lectures. While this may sound intimidating, it need not be. The resources for local history exist in abundance. State and local historical societies frequently have diaries and memoirs which might be used to add a personal flavor to a given lecture. Newspapers include a wealth of information which could be used for similar purposes. Quotations from the letters or diary of an early settler's wife, for example, might help convey a sense of the hardship and isolation encountered by pioneer women. A newspaper 
account of a meeting of local populists could impart the urgency and outrage felt by farmers in the 1890s, or a human interest story focusing on a local foreclosure sale might contribute more toward student understanding of the Great Depression than all of the statistics one could present.

City directories, the federal census, and especially the array of records available in the city hall and county courthouse, also contain a vast amount of information on local history. Such records are difficult to use, but they too can provide effective illustrations for the survey. The files of the county court or county sheriff, for example, might contain highly interesting accounts of local bootlegging activities in the 1920s. County welfare records could be used to illustrate efforts to cope with the human consequences of the great depression and the near bankruptcy of local government which resulted. City zoning ordinances and building permits might reveal patterns which could be used to describe the urban sprawl of the 1950s and 1960s. Title abstracts and deeds might provide examples of the restrictive convenants used to confine racial minorities within defined neighborhoods. The possibilities are endless.

There are easier ways of developing a set of survey lectures. One can find accounts of foreclosure sales, populist meetings, and the like in numerous monographs and anthologies. But such events take on a special meaning if they happened locally. Only then can they convey that essential link between the abstract national developments which must be illuminated in the survey and the more defined, local perspective of the students. By drawing examples from within that perspective, we can both heighten student interest in and enhance their understanding of our lectures.

Obviously, the use of local examples cannot solve all of the problems one encounters in teaching the survey. It cannot convey the subtle complexity of the Cold War or help students understand the emergence of the imperial presidency. It cannot completely eliminate the sterility of the large lecture classroom or the distance between student and instructor which the classroom creates. But if used selectively and with care, local examples can add interest and relevance to survey lectures. Finding those examples is hard work, but given the importance of the survey to the health of our departments and the future of the discipline, the effort would appear to be justified.

\section{NOTES}

$1_{1967,12 .}$ 